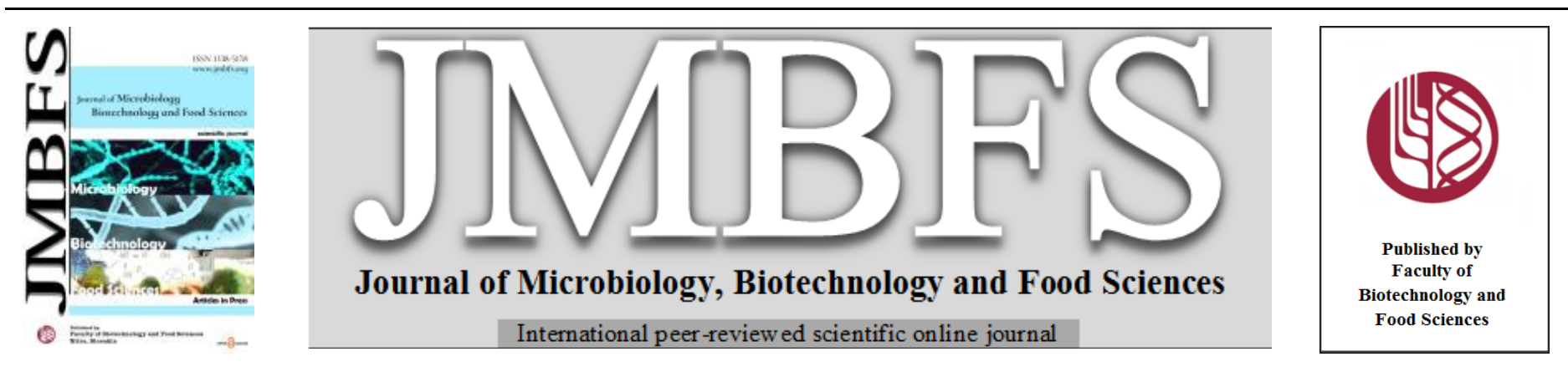

\title{
WGS CHARACTERIZATION OF ENTEROCOCCUS FAECALIS H1041 ISOLATED FROM THE TRADITIONAL BULGARIAN GREEN CHEESE
}

\author{
Svetoslav G. Dimov*l, Dimitrina Georgieva-Miteva ${ }^{1}$, Tereza Dekova ${ }^{1}$, Meglena Kitanova $^{l}$, Slavil Peykov ${ }^{1}$, Tanya Strateva $^{2}$ \\ Address(es): Assoc. Prof. Svetoslav Dimov, Sofia University “St. Kliment Ohridski”, Faculty of Biology, Dept. of Genetics; 8, Dragan Tzankov Blvd., 1164 - Sofia,
} Bulgaria.

${ }^{1}$ Sofia University “St. Kliment Ohridski”, Faculty of Biology, Dept. of Genetics; 8, Dragan Tzankov Blvd., 1164 - Sofia, Bulgaria.

${ }^{2}$ Medical University - Sofia, Faculty of Medicine, Dept. of Medical Microbiology; 2, Zdrave Str., 1431 - Sofia, Bulgaria.

*Corresponding author: svetoslav@ biofac.uni-sofia.bg

https://doi.org/10.55251/jmbfs.5203

\section{ARTICLE INFO}

Received 22. 8. 2021

Revised 9. 12. 2021

Accepted 12. 1.2022

Published 1. 6. 2022

Regular article

OPEN $\partial_{\text {ACCESS }}$

\begin{abstract}
In this study, Enterococcus faecalis H1041 which was isolated from the traditional Bulgarian green cheese was characterized in depth by a whole-genome sequencing performed on the Illumina HiSeq platform using 2 x 150 bases paired-end reads mode. The bioinformatic analysis performed only with free online tools revealed that the strain resembles other cheese-born E. faecalis strains by its antibiotics' resistances and virulence genotype, thus its presence within the green cheese should not be considered as a health risk. Only two antibiotic resistance genetic determinants were found, but they both carry mutations, and probably are not functional. Furthermore, 18 virulence factor genetic determinants were found, but only 6 of them possessed $100 \%$ identities with the canonical sequences, and being more or less intrinsic for the Enterococcus genus. None of them were found on contigs that contain sequences with known plasmid origin of replication. Enterolysin A gene was also detected which most probably plays role in ripening process of the Bulgarian green cheese.
\end{abstract}

Keywords: Enterococcus faecalis; whole-genome sequencing (WGS); Bulgarian green cheese isolate

\section{INTRODUCTION}

The members of the Enterococcus genus have an ambiguous nature. Many of them are part of the mammalian and human gastrointestinal microflora, thus having the potential to be opportunistic pathogens causing nosocomial infections (McBride et al., 2007), while others play an important role in the dairy, meat, and other food industries, participating in the fermentation processes and contributing to the organoleptic properties of the foods (Ogier and Serror, 2008). They also could have a protective role in food ripening by inhibiting pathogen species as reported (Álvarez et al., 2020). This implies that in every case a new Enterococcus strain is isolated from a food source, before declaring it safe for use, a complete characterization is obligatory. This characterization includes exact taxonomic identification, antibiotic resistances description, and presence of virulence factors (Ogier and Serror, 2008).

The Bulgarian green cheese is the only kind of cheese in Bulgaria which ripening is marked out by noble molds. This cheese which is considered as a part of the national cultural heritage is produced artisanally from raw ewe's or goat's milk only in the village Tcherni Vit (Teteven municipality). As no starter culture is added, it relies only on environmental microbiota, most probably depending on the specific climatic conditions in the village, which explains the geographic limitations of its production.

In this study, we used the Illumina HiSeq NGS platform generating 2 x 150 bases paired-end reads to characterize an E. faecalis isolate from Bulgarian green cheese, which was revealed to be a fast, cost- and labor-effective method for the assessment of newly isolated food-borne bacterial strains.

\section{MATERIALS AND METHODS}

\section{Strains isolation}

$50 \mathrm{mg}$ from the core part of the Bulgarian green cheese were taken off in sterile conditions, and homogenized within $1 \mathrm{ml}$ of sterile peptone water (PW). 10-fold serial dilutions in PW were made up to $10^{-4}$, then $100 \mu \mathrm{l}$ of the $10^{-3}$ and $10^{-4}$ dilutions were plated on Petri dishes containing the selective medium D-coccosel (Bioméruex). After incubation for $36-48$ hours at $30{ }^{\circ} \mathrm{C}$, colonies with black halos appeared which were picked up and inoculated in $3 \mathrm{ml}$ BHI liquid broth, and incubated at $30{ }^{\circ} \mathrm{C}$ for 24 hours. After that period ten isolates were plated on a BHI $1.5 \%$ agar with a sterile loop by the agar streaking method, and incubated at $30{ }^{\circ} \mathrm{C}$ for 24 hours. The cultures were monitored microscopically for contamination Stocks in skim milk were prepared from each isolate which were kept at $-70{ }^{\circ} \mathrm{C}$.

\section{Species identification}

A polyphase approach including other biochemical and physiological tests was used for the characterization of the isolates. They included the ability to grow in liquid medium at low and high temperatures, as well in the presence of $6.5 \% \mathrm{NaCl}$ (Leclerc et al., 1996). For each of these experiments, a single colony of the isolates was inoculated in $3 \mathrm{ml} \mathrm{BHI}$ broth and incubated for a week at $10^{\circ} \mathrm{C}$, overnight at $45{ }^{\circ} \mathrm{C}$ and 72 hours at $30{ }^{\circ} \mathrm{C}$ in BHI broth supplemented with $6.5 \% \mathrm{NaCl}$. Total DNA was isolated by "Gram Plus \& Yeast Genomic DNA Purification Kit", cat № 3585 (EURx), according to the manufacturer's instructions. The DNA concentrations were determined on a Quantus fluorimeter (Promega), while the quality was checked by $0.8 \%$ agarose gel electrophoresis. The isolates were further subjected to genus- and species-specific PCRs. All primers are listed in Table 1. Enterococcus sp. genus-specific PCR was performed accordingly $\mathrm{Ke}$ et al. (Ke et al., 1999). PCR amplification with E. faecalis specific primers EDA1_F1/EDA1_R1 was carried out as described by Peykov et al. (Peykov et al., 2012), while PCR amplification with E. durans specific primers DU1/DU2 as described by Jackson et al. (Jackson et al., 2004). The specific reactions' conditions are listed in Table 2. After the completion of the PCR reactions, $5 \mu 1$ of the PCR products were analyzed by electrophoresis on a $1.6 \%$ agarose gel in a TBE buffer system, followed by staining with GelRed ${ }^{\mathrm{TM}}$ (Sigma-Aldrich). To check their clonal relatedness, all the isolates were subjected to RAPD analyses as previously described (Gyurova et al., 2021). 
Table 1 PCR primers used in this study.

\begin{tabular}{|c|c|c|c|c|c|}
\hline Target & $\begin{array}{l}\text { Primer } \\
\text { pairs }\end{array}$ & Sequence $\left(5^{\prime}-3^{\prime}\right)$ & $\begin{array}{l}\text { Product } \\
\text { size (bp) }\end{array}$ & $\begin{array}{c}\text { Annealing } \\
\text { temperature }\left({ }^{\circ} \mathrm{C}\right)\end{array}$ & Source \\
\hline \multicolumn{6}{|c|}{ Genus-specific primers } \\
\hline tuf gene encoding & Ent1 & 5'-TACTGACAAACCATTCATGATG-3' & \multirow{2}{*}{112 bp } & \multirow{2}{*}{$55^{\circ} \mathrm{C}$} & \multirow{2}{*}{ (Ke et al., 1999) } \\
\hline EF-Tu & Ent2 & 5'-AACTTCGTCACCAACGCGAAC-3' & & & \\
\hline \multicolumn{6}{|c|}{ Species-specific primers } \\
\hline eda gene encoding & EDA1_F1 & 5'-GGGGACAGTTTTGGATGCTA-3' & \multirow{2}{*}{404 bp } & \multirow{2}{*}{$51^{\circ} \mathrm{C}$} & \multirow{2}{*}{$\begin{array}{c}\text { (Peykov et al., } \\
\text { 2012) }\end{array}$} \\
\hline KDPG aldolase & EDA1_R1 & 5'-TCCATATAGGCTTGGGCAAC-3' & & & \\
\hline \multirow{2}{*}{$\begin{array}{l}\text { soda gene, } \\
\text { encoding } \\
\text { superoxide } \\
\text { dismutase }\end{array}$} & DU1 & 5'-CCTACTGATATTAAGACAGCG-3' & \multirow[b]{2}{*}{295 bp } & \multirow[b]{2}{*}{$55^{\circ} \mathrm{C}$} & \multirow[b]{2}{*}{$\begin{array}{c}\text { (Jackson et al. } \\
\text { 2004) }\end{array}$} \\
\hline & DU2 & 5'-TAATCCTAAGATAGGTGTTTG-3' & & & \\
\hline \multirow{3}{*}{$\begin{array}{l}\text { 16S ribosomal } \\
\text { RNA gene }\end{array}$} & $27 \mathrm{~F}$ & 5'-AGAGTTTGATCMTGGCTCAG-3' & \multirow{2}{*}{1465 bp } & \multirow{2}{*}{$52{ }^{\circ} \mathrm{C}$} & \multirow{2}{*}{ (Lane, 1991) } \\
\hline & $1492 \mathrm{R}$ & 5'-ACCTTGTTACGACTT-3' & & & \\
\hline & & RAPD primers & & & \\
\hline $\mathrm{n} / \mathrm{a}$ & E1 & 5'-TCACGCTGCA-3' & $\mathrm{n} / \mathrm{a}$ & $\mathrm{n} / \mathrm{a}$ & $\begin{array}{c}\text { (Barbier et al. } \\
\text { 1996) }\end{array}$ \\
\hline $\mathrm{n} / \mathrm{a}$ & L2 & 5'-ATGTAACGCC-3' & $\mathrm{n} / \mathrm{a}$ & $\mathrm{n} / \mathrm{a}$ & $\begin{array}{c}\text { (Fitzsimons et al. } \\
1999 \text { ) }\end{array}$ \\
\hline
\end{tabular}

Table 2 PCR reactions conditions used in this study

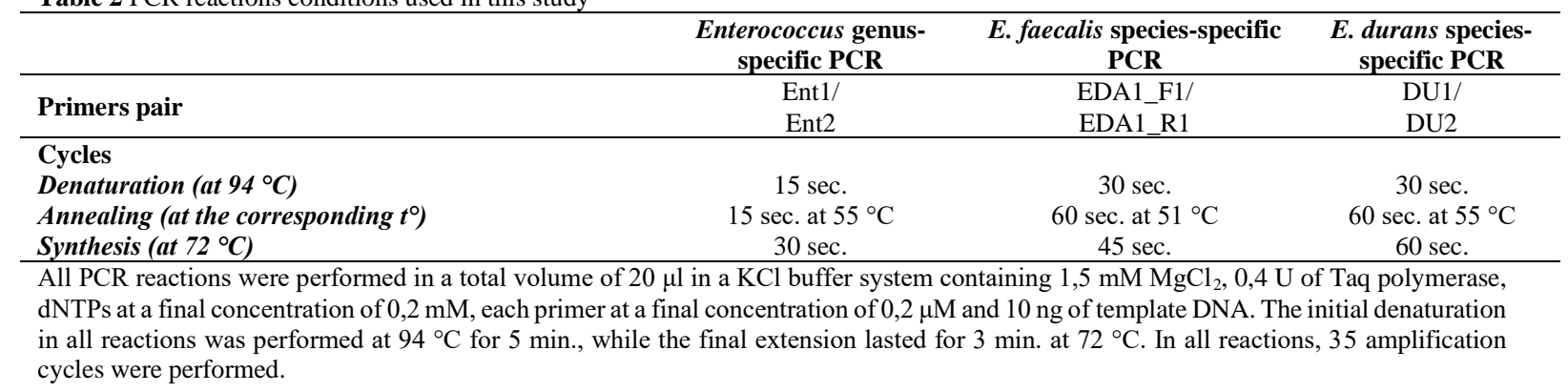

\section{Whole genome sequencing and data analyses}

Whole Genome Sequencing of E. faecalis H1041 was performed on the Illumina HiSeq platform, via $2 \times 150$ bp paired-end sequencing (Novogene, UK). The library construction was performed by Novogene. Sequencing data were pre-processed and assembled using the Shovill assembly pipeline for Illumina paired-end reads that is integrated into the Galaxy web-based platform (Afgan et al., 2018; Seemann, 2017). Next, the resulting assembly was evaluated using QUAST (Gurevich et al., 2013). MLST typing was performed on the MLST server (Larsen et al., 2012). In addition, the fasta-file with the draft genome sequence was uploaded to ResFinderFG 1.0 (https://cge.cbs.dtu.dk/services/ResFinderFG/) and VirulenceFinder 2.0 (https://cge.cbs.dtu.dk/services/VirulenceFinder/) servers to test for the presence of antibiotic resistance determinants and virulence factors in this isolate (Joensen et al., 2014; Zankari et al., 2012). The scan for plasmid origins of replication within the assembled contigs was performed by the PlasmidFinder 2.1. online tool (https://cge.cbs.dtu.dk/services/PlasmidFinder/) (Carattoli and Hasman, 2020). Putative bacteriocin open reading frames (ORF), immunity genes and transporters sequences were identified from the draft genome sequences through BAGEL4 (http://bagel4.molgenrug.nl/index.php) using default setting (de Jong et al., 2010). The exact locations of the putative bacteriocin ORFs were determined using the tblastn algorithm (Camacho et al., 2009).

\section{RESULTS AND DISCUSSION}

The ability of the isolates to grow on D-coccosel medium producing black halos around the colonies is indicative that they belong to the Enterococcus genus because of the ability to hydrolyze esculin (Facklam and Moody, 1970). Their genus affiliation was further confirmed by other classical approaches as the abilities to grow at low and high temperatures, as well as in the presence of $6.5 \%$
$\mathrm{NaCl}$ (Leclerc et al., 1996). Next, DNA-based approaches were used for confirmation of the results of the physiological tests. They included genus- and species-specific PCRs performed with genus-specific primers (Ke et al., 1999), $E$. durans specific primers (Jackson et al., 2004), and E. faecalis specific primers (Peykov et al., 2012). Positive results were obtained only with the genus-specific PCR as well as with the PCR performed with the E. faecalis specific primers, meaning that the isolates belonged to this species. When the clonal relatedness of the isolates was studied with RAPD analyzes with primers L2 and E1, lowest similarity coefficients of $91,4 \%$ and $96,2 \%$ respectively were obtained. As the generally accepted thresholds for clonal relatedness are 70\%-75\% (Grundmann et al., 1997; Webster et al., 1996), this means that all the 10 isolates belong to a single strain which was named H1041.

To assess the role of E. faecalis $\mathrm{H} 1041$ for the Bulgarian green cheese ripening, as well as to consider its application in the food industry, we chose to sequence its entire genome on the Illumina HiSeq platform because the information obtained would permit in one single experiment to type exactly the strain, to evaluate its potential to be pathogenic, as well as to check it for the presence of antibiotics resistances genes, bacteriocins genetic determinants, etc. The detailed statistics for the quality of sequencing data are shown in Table 3, which indicates that the sequencing is of good quality, allowing to proceed with the draft genome assembly. It was performed by the Shovill assembly pipeline for Illumina paired-end reads on the Galaxy web-based platform (Afgan et al., 2018; Seemann, 2017). The processing resulted in 91 contigs, from which 28 were larger than $1000 \mathrm{bp}$, the largest one being $455750 \mathrm{bp}$. The total length of the genome was 2944653 with a GC content of $37.4 \%$. These values are in agreement with those for E. faecalis with publically available genomes on NCBI's GenBank server. The data was uploaded to the GenBank server for public availability (accession number PRJNA682033 and ID: 682033).

Table 3 Statistics for the quality of sequencing data

\begin{tabular}{|c|c|c|c|c|c|c|c|c|}
\hline Sample & $\begin{array}{l}\text { Library Flowcell } \\
\text { Lane }\end{array}$ & $\begin{array}{l}\text { Raw } \\
\text { reads }\end{array}$ & $\begin{array}{l}\text { Raw } \\
\text { data } \\
\text { (Gb) }\end{array}$ & $\begin{array}{l}\text { Effective } \\
\text { reads }(\%)\end{array}$ & $\begin{array}{c}\text { Error } \\
\text { rate }(\%)\end{array}$ & Q20(\%) & Q30(\%) & $\mathrm{GC}(\%)$ \\
\hline \multirow{2}{*}{ H1041 } & $\begin{array}{c}\text { FDSW202493774- } \\
\text { 1r_HCLFNDSXY_L4 }\end{array}$ & 5130998 & \multirow{2}{*}{1.6} & 99.91 & 0.03 & 97.99 & 93.60 & 38.27 \\
\hline & $\begin{array}{l}\text { FDSW202493774- } \\
\text { 1r HF75CDSXY L1 }\end{array}$ & 5791302 & & 99.92 & 0.02 & 98.70 & 95.31 & 38.22 \\
\hline
\end{tabular}


Table 3 Statistics for the quality of sequencing data

\begin{tabular}{|c|c|c|c|c|c|c|c|c|}
\hline Sample & $\begin{array}{l}\text { Library Flowcell } \\
\text { Lane }\end{array}$ & $\begin{array}{l}\text { Raw } \\
\text { reads }\end{array}$ & $\begin{array}{l}\text { Raw } \\
\text { data } \\
\text { (Gb) }\end{array}$ & $\begin{array}{l}\text { Effective } \\
\text { reads (\%) }\end{array}$ & $\begin{array}{c}\text { Error } \\
\text { rate }(\%)\end{array}$ & Q20(\%) & Q30(\%) & $\mathrm{GC}(\%)$ \\
\hline
\end{tabular}

Legend: Library Flowcell Lane: Library ID Flowcell ID lane ID; Raw reads: the total amount of reads of raw data; Raw data: the total length of the reads, calculated in gigabases $(\mathrm{Gb})$; Effective reads: percentage of the clean reads; Error rate: base error rate; Q20 and Q30: percentages of the base counts with Phred values of more than 20 and 30, respectively; GC: percentage of the G \& C base counts

The MLST analysis was performed on the MLST server (Larsen et al., 2012), and it attributed E. faecalis $\mathrm{H} 1041$ to the sequence type 220 , showing $100 \%$ sequence identity with this type's allele variants: $a r o E \_9, g d h \_27, g k i \_12, g y d \_6, p s t S \_23$, xpt_10, and yqiL_7. E. faecalis ST 220 isolates were reported most often to be from an animal origin (Olsen et al., 2012; Si et al., 2015) which can explain the presence of our strain in a dairy product that was prepared from raw milk.

First, the E. faecalis $\mathrm{H} 1041$ was scanned for the presence of antibiotics resistance genetic determinants by the ResFinderFG 1.0 tool. The results are presented in

Table 4 and Fig. 1. Tetracycline and trimethoprim resistance genetic determinants were found on contigs 16 and 1 respectively. However, the similarity to the reference sequences was not complete due to 17 and 4 nucleotide substitutions found in TetM and dihydrofolate reductase genes. Despite not knowing the effect of these point mutations, their high number, as well the fact that the BLAST analysis we ran with the canonical sequences, didn't show variants within the GenBank's database which were similar to ours, allow speculations that these genes are probably not functional because they have never been reported till now.

Table 4 ResFinderFG 1.0 results

\begin{tabular}{lllllll}
\hline Hit name & Identity & Query/HSP & Contig & Position in contig & $\begin{array}{l}\text { Drug } \\
\text { treatment }\end{array}$ & $\begin{array}{l}\text { NCBI accession } \\
\text { number }\end{array}$ \\
\hline $\begin{array}{l}\text { spanning Tet(M) and variants } \\
\text { dihydrofolate reductase }\end{array}$ & 99.02 & $1935 / 1935$ & Contig 16 & $12364 . .14298$ & Tetracycline & KU543782.1 \\
\hline
\end{tabular}

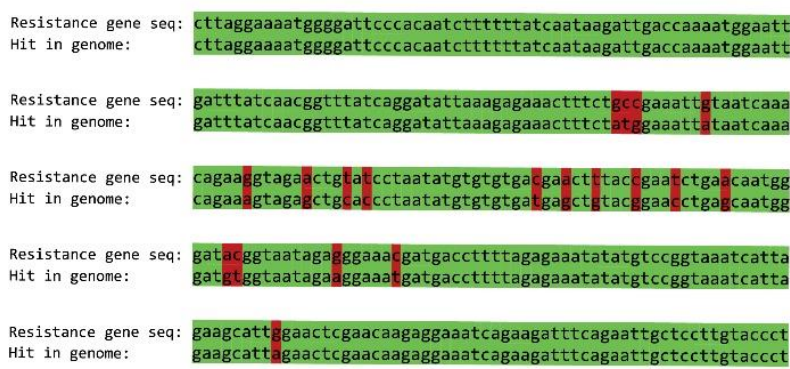

dihydrofolate reductase

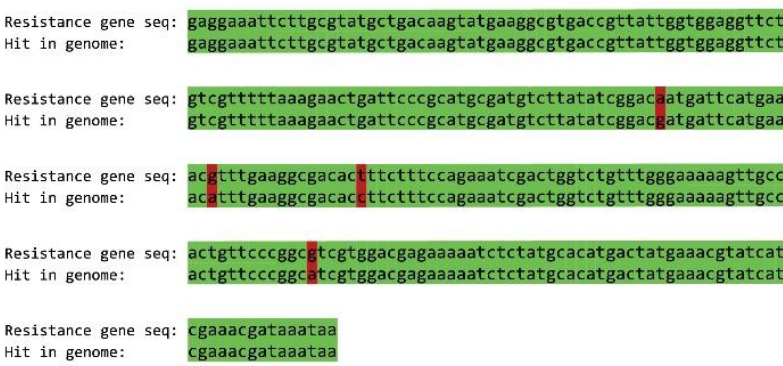

Figure 1 Partial alignment of the tet(M) (left panel) and the dhfr genes (right) panel of E. faecalis H1041 (up), carrying mutations, and the canonical sequences (down). The nucleotide substitutions are highlighted in red.

Next, we uploaded the assembled genome to the VirulenceFinder 2.0 server. In total, 18 virulence factors were reported (Table 5). However, $100 \%$ nucleotide identity to the corresponding reference sequences was reported for only 6 of them - ElrA, SrtA, efaAfs, fsrB, gelE, and tpx. ElrA encodes an internalin-like protein that prevents the adhesion to macrophages (Nunez et al., 2018). StrA is a sortase enzyme that is essential for biofilm formation (Das et al., 2018) together with the $f_{s r B}$ (Gaspar et al., 2009). tpx encodes a thiol peroxidase determining oxidative stress resistance (Elghaieb et al., 2019). efaAfs encodes an adhesin protein, while gelE - a gelatinase enzyme (Zhong et al., 2021), both believed to be more or less intrinsic for the genus (Fiore et al., 2019). The presence of these intact virulence factors within the genome of a strain isolated from a dairy product could raise some well-motivated concerns. However, in the scientific literature, many reports exis where food-derived enterococci carry many of these genes, and some of the others listed in Table 5, in more or less similar combinations - in fermented meats (Barbosa et al., 2010), ready-to-eat salads (Campos et al., 2013), and retail meat (Elghaieb et al., 2019; Golob et al., 2019). Considering all these facts the virulence genetic profile of E. faecalis $\mathrm{H} 1041$ is not an exception for a traditional raw milk dairy product, and does not obligatory imply to be a health concern as it was the case of some other artisanal cheeses (Câmara et al., 2020).

Table 5 VirulenceFinder 2.0 results

\begin{tabular}{|c|c|c|c|c|c|c|}
\hline $\begin{array}{l}\text { Virulence } \\
\text { factor }\end{array}$ & Identity & $\begin{array}{l}\text { Query / } \\
\text { Template } \\
\text { length }\end{array}$ & Contig & $\begin{array}{l}\text { Position in } \\
\text { contig }\end{array}$ & Protein function & $\begin{array}{l}\text { NCBI } \\
\text { accession } \\
\text { number }\end{array}$ \\
\hline EIrA & 100 & $2172 / 2172$ & Contig 10 & $3499 . .5670$ & & CP003726.1 \\
\hline SrtA & 100 & $735 / 735$ & Contig 8 & $58242 . .58976$ & & CP003726.1 \\
\hline ace & 98.07 & $2025 / 2025$ & Contig 2 & $248603 . .250627$ & collagen adhesin precursor & AE016830.1 \\
\hline cCF10 & 99.76 & $828 / 828$ & Contig 12 & $97546 . .98373$ & & СР002491.1 \\
\hline cCF10 & 99.76 & $828 / 828$ & Contig 12 & $97546 . .98373$ & & СР002621.1 \\
\hline cOB1 & 99.88 & $819 / 819$ & Contig 3 & $128672 . .129490$ & & СР002491.1 \\
\hline $\mathrm{cad}$ & 99.78 & $930 / 930$ & Contig 9 & $4676 . .5605$ & & СР002621.1 \\
\hline camE & 99.4 & $501 / 501$ & Contig 14 & $88451 \ldots 88951$ & sex pheromone cAM373 precursor & AF435437.1 \\
\hline camE & 99.4 & $501 / 501$ & Contig 14 & $88451 . .88951$ & sex pheromone cAM373 precursor & AF435438.1 \\
\hline camE & 99.4 & $501 / 501$ & Contig 14 & $88451 \ldots 88951$ & sex pheromone cAM373 precursor & AF435439.1 \\
\hline ebpA & 99.7 & $3312 / 3312$ & Contig 2 & $260557 . .263868$ & & 295112306 \\
\hline ebpB & 99.86 & $1431 / 1431$ & Contig 2 & $259123 . .260553$ & & СР002491.1 \\
\hline efaAfs & 100 & $927 / 927$ & Contig 5 & $45134 . .46060$ & & CP003726.1 \\
\hline fsrB & 100 & $729 / 729$ & Contig 17 & $11545 . .12273$ & biofilm formation & CP003726.1 \\
\hline gelE & 100 & $1530 / 1530$ & Contig 17 & 13851..15380 & & CP003726.1 \\
\hline hylA & 99.94 & $3266 / 3266$ & Contig 8 & $82724 . .85989$ & & СР003726.1 \\
\hline hylB & 99.4 & $3015 / 3015$ & Contig 4 & $19754 . .22768$ & & СР002621.1 \\
\hline tpx & 100 & $510 / 510$ & Contig 15 & 40489..40998 & & CP003726.1 \\
\hline
\end{tabular}


One of the characteristics of pathogenic enterococcal strains is that they contain plasmids harboring virulence factors genes, as well as antibiotics resistances genes. In the case of E. faecalis $\mathrm{H} 1041$ only one hit was obtained with the PlasmidFinder tool: the origin of replication rep $9 b$ of a RepA_N-type plasmid (GenBank accession No. CP002494) found on Contig 16 with $100 \%$ sequence identity. This type of plasmids is broadly distributed among Gram-positive bacteria but they have a narrow host range and the intergeneric transfers are rare because of the reported co-evolution with the host (Weaver et al., 2009). None of the genetic determinants of the virulence factors detected were positioned on Contig 16, and only the mutations carrying the copy of the tetracycline resistance gene was on the same contig (Fig. 1, Table 4). The probably not functioning copy of the Tet $(M)$, the lack of plasmid-associated virulence factors genes, and the strongly limited rates of the plasmid's transfers indicate that the presence of this plasmid within E. faecalis H1041 should not be regarded as a pathogenicity trait.
H1041 contigs.fasta AOI_01

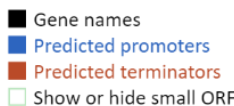

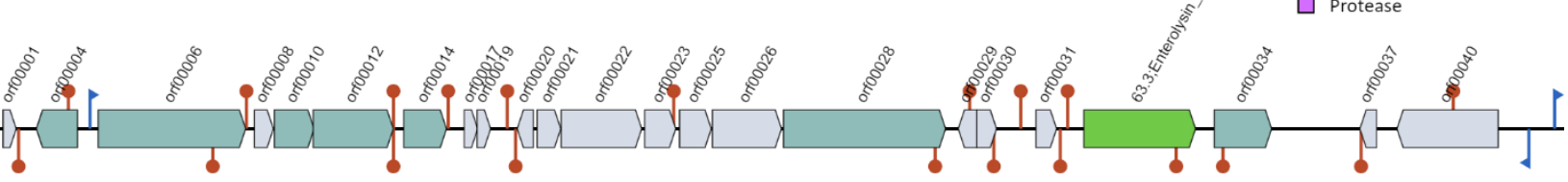

Figure 2 Organization of the genetic cluster containing the enterolysin A gene.

Finally, the assembled contigs were scanned for the presence of bacteriocin encoding genetic determinants using the BAGEL4 online tool. Only one genetic cluster was found - that of enterolysin A, positioned on contig 5 (Fig. 2). Enterolysin A is a well-characterized bacteriocin (a metalloendopeptidase) that is typical for many E. faecalis strains, and that is known to inhibit the growth of closely related species and genera such as other enterococci, pediococci, lactobacilli, and lactococci by a bacteriolytic mode of action (Nilsen et al., 2003) The presence of enterolysin A has nothing to do with the presence or absence of pathogenicity characteristics, but rather with the cheese ripening process - the autolysis of the lactic acid bacteria of the starter cultures is important for the development of the flavor and to the debittering occurring during the cheese ripening (Crow et al., 1995; Hickey et al., 2004). So, in this regard, E. faecalis $\mathrm{H} 1041$ is a typical dairy strain.

\section{CONCLUSION}

Pathogenic Enterococci are not highly virulent, and till now enterococcal infections have never been linked to cheese consumption (Dapkevicius et al., 2021). Cheese and other food-borne enterococci usually harbor few virulence factors and antibiotic resistance genes, a fact that does not mean that they are obligatory pathogens, every case requiring an individual study (Deng et al., 2021). In this regard, E. faecalis $\mathrm{H} 1041$ is a typical dairy representative of the species, which contributes to the development of the organoleptic properties of the Bulgarian green cheese. It should not be considered as a health risk, especially because of the lack of vancomycins' resistances, as well as because of the presence of numerous mutations within the two antibiotics resistances genes found. Finally, the WGS technology which was chosen to characterize E. faecalis $\mathrm{H} 1041$ revealed to be a cost efficient and fast method for in depth characterization and assessment of the pathogenicity potential of newly isolated enterococcal strains.

Acknowledgments: The authors would like to express their gratitude to $\mathrm{Mr}$ Tsvetan Dimitrov from the non-governmental organization "Green cheese", 5725 - Tcherni Vit, Bulgaria, for providing Bulgarian green cheese samples.

\section{REFERENCES}

Afgan, E., Baker, D., Batut, B., van den Beek, M., Bouvier, D., Čech, M., Chilton, J., Clements, D., Coraor, N., Grüning, B.A., Guerler, A., Hillman-Jackson, J., Hiltemann, S., Jalili, V., Rasche, H., Soranzo, N., Goecks, J., Taylor, J., Nekrutenko, A., Blankenberg, D., 2018. The Galaxy platform for accessible, reproducible and collaborative biomedical analyses: 2018 update. Nucleic Acids Research 46, W537-W544. https://doi.org/10.1093/nar/gky379

Álvarez, M., Rodríguez, A., Peromingo, B., Núñez, F., Rodríguez, M., 2020. Enterococcus faecium: a promising protective culture to control growth of ochratoxigenic moulds and mycotoxin production in dry-fermented sausages. Mycotoxin Research 36, 137-145. https://doi.org/10.1007/s12550-019-00376-6

Barbosa, J., Gibbs, P.A., Teixeira, P., 2010. Virulence factors among enterococci isolated from traditional fermented meat products produced in the North of Portugal. Food Control 21, 651-656 https://doi.org/10.1016/j.ijfoodmicro.2015.10.016

Camacho, C., Coulouris, G., Avagyan, V., Ma, N., Papadopoulos, J., Bealer, K., Madden, T.L., 2009. BLAST+: architecture and applications. BMC Bioinformatics 10, 421. https://doi.org/10.1186/1471-2105-10-421

Câmara, S.P.A., Dapkevicius, A., Silva, C.C.G., Malcata, F.X., L. N. Enes Dapkevicius, M., 2020. Artisanal Pico cheese as reservoir of Enterococcus species possessing virulence and antibiotic resistance properties: implications for food $\begin{array}{llll}\text { safety. } & \text { Food } & \text { Biotechnology } & 34,\end{array}$ https://doi.org/10.1080/08905436.2019.1710844

Campos, J., Mourão, J., Pestana, N., Peixe, L., Novais, C., Antunes, P., 2013. Microbiological quality of ready-to-eat salads: an underestimated vehicle of bacteria and clinically relevant antibiotic resistance genes. Int $\mathbf{J}$ Food Microbiol 166, 464-470. https://doi.org/10.1016/j.ijfoodmicro.2013.08.005

Carattoli, A., Hasman, H., 2020. PlasmidFinder and In Silico pMLST: Identification and Typing of Plasmid Replicons in Whole-Genome Sequencing (WGS), in: de la Cruz, F. (Ed.), Horizontal Gene Transfer: Methods and Protocols. Springer US, New York, NY, pp. 285-294.

Crow, V.L., Coolbear, T., Gopal, P.K., Martley, F.G., McKay, L.L., Riepe, H., 1995. The role of autolysis of lactic acid bacteria in the ripening of cheese International Dairy Journal 5, 855-875. https://doi.org/10.1007/978-1-4939-98777_20

Dapkevicius, M.d.L.E., Sgardioli, B., Câmara, S.P.A., Poeta, P., Malcata, F.X., 2021. Current Trends of Enterococci in Dairy Products: A Comprehensive Review of Their Multiple Roles. Foods 10, 821. https://doi.org/10.3390/foods10040821

Das, S., Srivastava, V.K., Parray, Z.A., Jyoti, A., Islam, A., Kaushik, S., 2018. Identification of potential inhibitors of sortase A: Binding studies, in-silico docking and protein-protein interaction studies of sortase A from Enterococcus faecalis. International Journal of Biological Macromolecules 120, 1906-1916 https://doi.org/10.1016/j.ijbiomac.2018.09.174

de Jong, A., van Heel, A.J., Kok, J., Kuipers, O.P., 2010. BAGEL2: mining for bacteriocins in genomic data. Nucleic Acids Research 38, W647-W651 https://doi.org/10.1093/nar/gkq365

Deng, F., Chen, Y., Zhou, X., Xiao, H., Sun, T., Deng, Y., Wen, J., 2021. New Insights into the Virulence Traits and Antibiotic Resistance of Enterococci Isolated from Diverse Probiotic Products. Microorganisms 9, 726. https://doi.org/10.3390/microorganisms9040726

Elghaieb, H., Tedim, A.P., Abbassi, M.S., Novais, C., Duarte, B., Hassen, A. Peixe, L., Freitas, A.R., 2019. From farm to fork: identical clones and Tn6674-like elements in linezolid-resistant Enterococcus faecalis from food-producing animals and retail meat. Journal of Antimicrobial Chemotherapy 75, 30-35 https://doi.org/10.1093/jac/dkz419

Facklam, R.R., Moody, M.D., 1970. Presumptive Identification of Group D Streptococci: the Bile-Esculin Test. Applied Microbiology 20, 245 250. https://doi.org/10.1128/am.20.2.245-250.1970

Fiore, E., Tyne, D.V., Gilmore, M.S., Fischetti, V.A., Novick, R.P., Ferretti, J.J., Portnoy, D.A., Braunstein, M., Rood, J.I., 2019. Pathogenicity of Enterococci. Microbiology Spectrum 7, 7.4.9. https://doi.org/10.1128/microbiolspec.GPP3$\underline{0053-2018}$

Gaspar, F., Teixeira, N., Rigottier-Gois, L., Marujo, P., Nielsen-LeRoux, C., Crespo, M.T.B., Lopes, M.d.F.S., Serror, P., 2009. Virulence of Enterococcus faecalis dairy strains in an insect model: the role of fsrB and gelE. Microbiology (Reading) 155, 3564-3571. https://doi.org/10.1099/mic.0.030775-0

Golob, M., Pate, M., Kušar, D., Dermota, U., Avberšek, J., Papić, B., Zdovc, I., 2019. Antimicrobial Resistance and Virulence Genes in Enterococcus faecium and Enterococcus faecalis from Humans and Retail Red Meat. BioMed Research International 2019, 2815279. https://doi.org/10.1155/2019/2815279

Grundmann, H.J., Towner, K.J., Dijkshoorn, L., Gerner-Smidt, P., Maher, M., Seifert, H., Vaneechoutte, M., 1997. Multicenter study using standardized protocols and reagents for evaluation of reproducibility of PCR-based fingerprinting of Acinetobacter spp. Journal of clinical microbiology 35, 30713077. https://doi.org/10.1128/jcm.35.12.3071-3077.1997 
Gurevich, A., Saveliev, V., Vyahhi, N., Tesler, G., 2013. QUAST: quality assessment tool for genome assemblies. Bioinformatics 29, 1072-1075. https://doi.org/10.1093/bioinformatics/btt086

Gyurova, A., Vladimirova, A., Peykov, S., Dimitrov, M., Strateva, T., Dimov, S.G., 2021. Characterization of Enterococcus durans EDD2, a strain from beehives with inhibitory activity against Paenibacillus larvae. Journal of Apicultural Research, 1-14. https://doi.org/10.1080/00218839.2021.1936915

Hickey, R.M., Ross, R.P., Hill, C., 2004. Controlled Autolysis and Enzyme Release in a Recombinant Lactococcal Strain Expressing the $\begin{array}{llll}\text { Metalloendopeptidase } & \text { Enterolysin } & \text { A. } & 70,\end{array}$ 1748. https://doi.org/10.1128/AEM.70.3.1744-1748.2004

Jackson, C.R., Fedorka-Cray, P.J., Barrett, J.B., 2004. Use of a genus- and speciesspecific multiplex PCR for identification of enterococci. Journal of clinical microbiology 42, 3558-3565. https://doi.org/10.1128/JCM.42.8.3558-3565.2004 Joensen, K.G., Scheutz, F., Lund, O., Hasman, H., Kaas, R.S., Nielsen, E.M. Aarestrup, F.M., Carroll, K.C., 2014. Real-Time Whole-Genome Sequencing for Routine Typing, Surveillance, and Outbreak Detection of Verotoxigenic Escherichia coli. 52, 1501-1510. https://doi.org/10.1128/JCM.03617-13

Ke, D., Picard, F.J., Martineau, F., Ménard, C., Roy, P.H., Ouellette, M., Bergeron, M.G., 1999. Development of a PCR assay for rapid detection of enterococci. Journal of clinical microbiology 37, 3497-

3503. https://doi.org/10.1128/JCM.37.11.3497-3503.1999

Larsen, M.V., Cosentino, S., Rasmussen, S., Friis, C., Hasman, H., Marvig, R.L., Jelsbak, L., Sicheritz-Pontén, T., Ussery, D.W., Aarestrup, F.M., Lund, O., 2012. Multilocus sequence typing of total-genome-sequenced bacteria. Journal of clinical microbiology 50, 1355-1361. https://doi.org/10.1128/JCM.06094-11 Leclerc, H., Devriese, L.A., Mossel, D.A.A., 1996. Taxonomical changes in intestinal (faecal) enterococci and streptococci: consequences on their use as indicators of faecal contamination in drinking water. Journal of Applied Bacteriology 81, 459-466. https://doi.org/10.1111/j.1365-2672.1996.tb03533.x

McBride, S.M., Fischetti, V.A., LeBlanc, D.J., Moellering, R.C., Jr., Gilmore, M.S., 2007. Genetic Diversity among Enterococcus faecalis. PLOS ONE 2, e582. https://doi.org/10.1371/journal.pone.0000582

Nilsen, T., Nes, I.F., Holo, H., 2003. Enterolysin A, a Cell Wall-Degrading Bacteriocin from <i>Enterococcus faecalis $</ \mathrm{i}>\mathrm{LMG}$ 2333. Applied and environmental microbiology 69, 29752984. https://doi.org/10.1128/AEM.69.5.2975-2984.2003

Nunez, N., Derré-Bobillot, A., Gaubert, S., Herry, J.-M., Deschamps, J., Wei, Y., Baranek, T., Si-Tahar, M., Briandet, R., Serror, P., Archambaud, C., 2018. Exploration of the role of the virulence factor ElrA during Enterococcus faecalis cell infection. Scientific Reports 8, 1749. https://doi.org/10.1038/s41598-01820206-6

Ogier, J.-C., Serror, P., 2008. Safety assessment of dairy microorganisms: The Enterococcus genus. International Journal of Food Microbiology 126, 291-301. https://doi.org/10.1016/j.ijfoodmicro.2007.08.017

Olsen, R.H., Schønheyder, H.C., Christensen, H., Bisgaard, M., 2012. Enterococcus faecalis of Human and Poultry Origin Share Virulence Genes Supporting the Zoonotic Potential of E. faecalis. Zoonoses and Public Health 59, 256-263.

https://doi.org/10.1111/j.1863-2378.2011.01442.x

Peykov, S.Z., Aleksandrova, V.D., Dimov, S.G., 2012. Rapid identification of Enterococcus faecalis by species-specific primers based on the genes involved in the Entner-Doudoroff pathway. Mol Biol Rep 39, 70257030. https://doi.org/10.1007/s11033-012-1533-z

Seemann, T., 2017. Shovill: Faster SPAdes assembly of Illumina reads

Si, H., Zhang, W.-J., Chu, S., Wang, X.-M., Dai, L., Hua, X., Dong, Z., Schwarz, S., Liu, S., 2015. Novel plasmid-borne multidrug resistance gene cluster including lsa(E) from a linezolid-resistant Enterococcus faecium isolate of swine origin. Antimicrobial agents and chemotherapy 59, 7113 7116. https://doi.org/10.1128/AAC.01394-15

Weaver, K.E., Kwong, S.M., Firth, N., Francia, M.V., 2009. The RepA N replicons of Gram-positive bacteria: a family of broadly distributed but narrow $\begin{array}{lllll}\text { host range plasmids. } & \text { Plasmid } & \end{array}$ https://doi.org/10.1016/j.plasmid.2008.11.004

Webster, C.A., Towner, K.J., Humphreys, H., Ehrenstein, B., Hartung, D., Grundmann, H., 1996. Comparison of rapid automated laser fluorescence analysis of DNA fingerprints with four other computer-assisted approaches for studying relationships between Acinetobacter baumannii isolates. Journal of Medical Microbiology 44, 185-194. https://doi.org/10.1099/00222615-44-3-185

Zankari, E., Hasman, H., Cosentino, S., Vestergaard, M., Rasmussen, S., Lund, O. Aarestrup, F.M., Larsen, M.V., 2012. Identification of acquired antimicrobial resistance genes. Journal of Antimicrobial Chemotherapy 67, 26402644. https://doi.org/10.1093/jac/dks261

Zhong, R., Zhou, Z., Liu, H., Zhong, Z., Peng, G., 2021. Antimicrobial resistance and virulence factor gene profiles of Enterococcus spp. isolated from giant panda oral cavities. Journal of Veterinary Research 65, 147-154. https://doi.org/10.2478/jvetres-2021-0030 